Article

\title{
High-Strength Concrete Circular Columns with TRC-TSR Dual Internal Confinement
}

\author{
Rami Eid*(D, Avi Cohen, Reuven Guma, Eliav Ifrach, Netanel Levi and Avidor Zvi \\ Civil Engineering Department, SCE-Shamoon College of Engineering, Beer Sheva 8410802, Israel; \\ avicohen@ofaqim.muni.il (A.C.); reuven860@gmail.com (R.G.); Elifrah@gmail.com (E.I.); \\ netanellevi07@gmail.com (N.L.); avidorzvi@gmail.com (A.Z.) \\ * Correspondence: ramiei@sce.ac.il
}

Received: 24 September 2019; Accepted: 8 October 2019; Published: 14 October 2019

\begin{abstract}
The standard requirements for transverse steel reinforcement (TSR) confinement in reinforced-concrete $(\mathrm{RC})$ columns are mainly to provide the following: ductile behavior, minimum axial load capacity of the column's core, and prevention of longitudinal bars buckling. It is well-known that the passive confinement due the TSR action is less effective in high-strength concrete (HSC) compared to normal-strength concrete (NSC). Therefore, the TSR amounts required by the standards for HSC columns are high, and in some cases, especially in the lower stories columns of high-rise buildings, are impractical. This paper presents a new construction method using textile-reinforced concrete (TRC) as internal confinement together with reduced TSR amounts. Moreover, comparison of the proposed method with RC columns casted in fiber-reinforced polymer (FRP) stay-in-place forms as additional external confinement, is presented. Eleven large-scale column specimens were tested under axial compression. The results give an insight on the application feasibility of the proposed construction method. It is shown that the TRC-TSR dual internal confinement action can be an option to reduce the standard required TSR amounts while maintaining similar levels of ductile behavior.
\end{abstract}

Keywords: reinforced-concrete; textile-reinforced concrete; TRC; columns; fiber-reinforced polymer; FRP; ductility; transverse steel reinforcement; confinement

\section{Introduction}

The use of high-strength concrete (HSC) for columns has the advantage of reducing their dimensions [1]. The application of HSC for columns in the lower stories of high-rise buildings is a superior choice for contractors; however, the brittle behavior of the columns, especially those with high axial load levels, results in a high amount of the required transverse steel reinforcement (TSR) to provide the high level of passive confinement [2-4]. This confinement is crucial to provide the column the minimum level of ductility. Based on the leading standards [5-8] and as shown in Eid et al. [1], for a circular column which is not part of the seismic-force-resisting system (SFRS) with large diameter (a diameter of $D=1200 \mathrm{~mm}$ ), and a high axial load level, $P,\left(P / f_{c}^{\prime} A_{g}=0.5\right.$ as in the case of a column located at the lower stories of a high-rise building, where $f_{c}^{\prime}$ is the concrete compressive strength and $A_{g}$ is the gross area of the section), the TSR volumetric ratio, $\rho_{s}$, is in the range of $2.2-4.7 \%$ for a concrete compressive strength of $f_{c}^{\prime}=80 \mathrm{MPa}$. To satisfy these $\rho_{s}$ values, large diameters of TSR hoop bars $(25-30 \mathrm{~mm})$ at very small spacings $(80-50 \mathrm{~mm})$ are required. It should be noted that, for a column that is part of the SFRS, the required $\rho_{s}$ is significantly higher (4.4-6.5\%). Such a reinforcement amount is impractical from construction aspects. One of the methods that was proposed in the literature to reduce the TSR amount was to use a fiber-reinforced polymer (FRP) stay-in-place form to provide extra external confinement $[9,10]$. The main disadvantage of using FRP stay-in-place forms is their low fire resistance [11-13]. Studies have shown that for moderately high 
temperatures, the polymer of the FRP reaches its glass transition temperature and changes from a brittle to viscous material [13]. This results in the loss of the external confinement mechanism efficiency. Recent studies have shown that the use of external textile-reinforced mortar (TRM) or textile-reinforced concrete (TRC) to strengthen existing normal-strength concrete (NSC) columns can be efficient in terms of fire resistance and strength/ductility enhancement [14-19]. In order to utilize, on one hand, the high stiffness of the fibers in confining the concrete, and, on the other hand, to protect them from potential exposure to high fire temperatures, this paper examines the use of the fibers as an internal reinforcement in the shape of textile fibers. Thus, the fibers are incorporated with the conventional steel reinforcement cage producing a new dual confinement system of TRC and TSR.

The aim of this study is to examine the feasibility of the proposed confinement configuration, the TRC-TSR dual confinement system. Preliminary results were presented in the CICE 2018 conference [20]. The present study provides in detail the experimental research study performed on eleven large-scale HSC circular column specimens subjected to axial compression loading. The specimens include three different confinement configurations with similar confinement levels: conventional TSR, stay-in-place FRP-TSR, and TRC-TSR.

\section{Experimental Program}

Eleven large-scale, HSC-reinforced circular columns (250 diameter $\times 750 \mathrm{~mm}$ height) with different confinement reinforcement types were designed and tested (Figure 1). Six column specimens contained TRC-TSR, three FRP-TSR, and two TSR confinement. The aim in the design of the confinement amounts of TSR, TRC, and FRP was to keep the maximum equivalent lateral passive pressure [21] equal for all specimens. The specimens' names include the TSR volumetric ratio, $\rho_{s}$, the hoops bar diameter, $\phi_{h}$, and spacing, $s$, the type of the second confinement mechanism, that is, TRC (either inside or outside the steel cage - see Figure 1b,c) or FRP, and their number of layers. For example, specimen S1.4(10-95)T1In consists of $\rho_{s}=1.4 \%, \phi_{h}=10 \mathrm{~mm}, s=95 \mathrm{~mm}$, and one layer of TRC installed inside the steel reinforcement cage. Details of the specimens are presented in Figure 1 and Table 1.
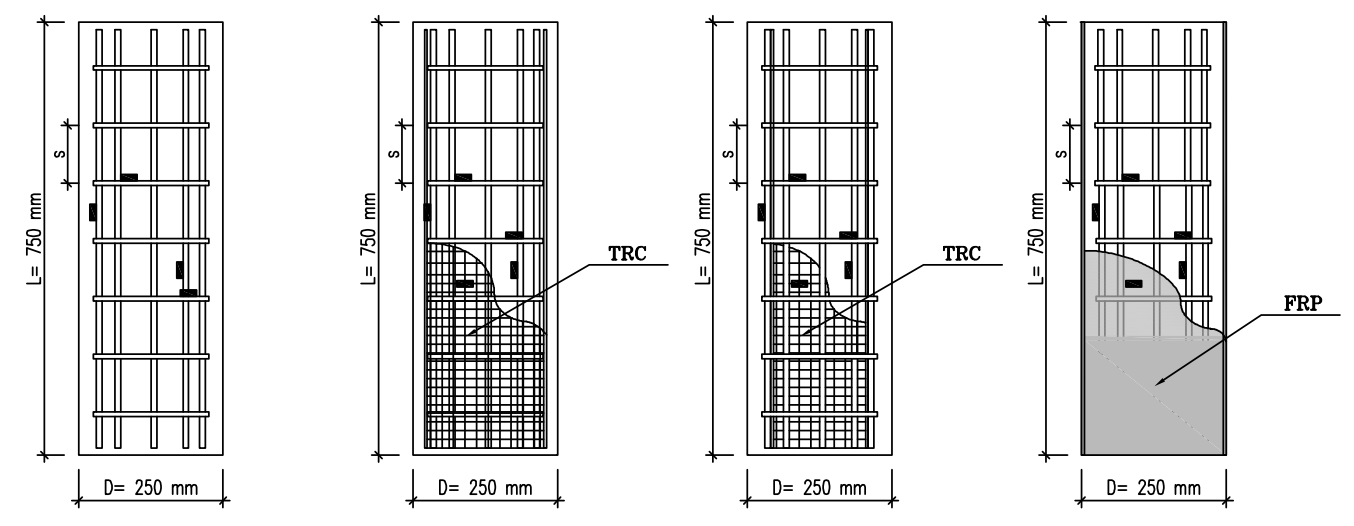

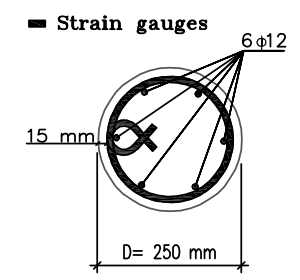

(a)

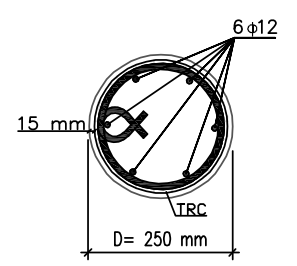

(b)

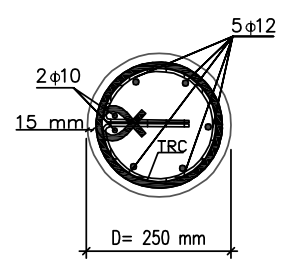

(c)

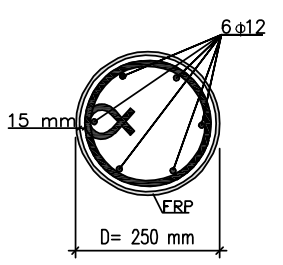

(d)

Figure 1. Geometrical and reinforcement properties of all HSC-tested columns. (a) TSR-confined specimens, (b) specimens with TRC wrapped externally around the reinforcement cage, (c) specimens with TRC located around the inner perimeter of the reinforcement cage, (d) FRP-TSR confined specimens. 
Table 1. Specimens' details.

\begin{tabular}{|c|c|c|c|c|c|c|c|c|c|c|c|c|c|}
\hline \multirow[b]{2}{*}{ Specimen } & \multirow[b]{2}{*}{$\begin{array}{c}f_{c}^{\prime} \\
\mathbf{( M P a})\end{array}$} & \multirow[b]{2}{*}{$\begin{array}{c}D \\
(\mathrm{~mm})\end{array}$} & \multirow[b]{2}{*}{$\begin{array}{c}L \\
(\mathbf{m m})\end{array}$} & \multicolumn{4}{|c|}{ TSR } & \multicolumn{3}{|c|}{ TRC } & \multicolumn{3}{|c|}{ FRP } \\
\hline & & & & $\begin{array}{c}f_{y h} \\
\text { (MPa) }\end{array}$ & $\begin{array}{c}\phi_{h} \\
(\mathrm{~mm})\end{array}$ & $\begin{array}{c}s \\
(\mathrm{~mm})\end{array}$ & $\begin{array}{l}\rho_{s} \\
(\%)\end{array}$ & $\begin{array}{c}E_{f} \\
(\mathrm{GPa})\end{array}$ & $n_{T R C}^{*}$ & $\begin{array}{c}t_{T R C} \\
(\mathrm{~mm})\end{array}$ & $\begin{array}{c}E_{f} \\
\text { (GPa) }\end{array}$ & $n_{F R P}$ & $\begin{array}{c}t_{T R C} \\
(\mathrm{~mm})\end{array}$ \\
\hline $\mathrm{S} 2.3(10-60) \mathrm{T} / \mathrm{F} 0$ & & & & 548 & 10 & 60 & 2.27 & & - & - & & - & - \\
\hline S2.3(12-85)T/F0 & & & & 580 & 12 & 85 & 2.29 & & - & - & & - & - \\
\hline S1.4(10-95)T1E & & & & 548 & 10 & 95 & 1.43 & & 1 (ext.) & 0.0785 & & - & - \\
\hline S1.4(10-95)T1In & & & & 548 & 10 & 95 & 1.43 & & 1 (int.) & 0.0785 & & - & - \\
\hline S0.9(10-160)T1In & & & & 548 & 10 & 160 & 0.85 & 240 & 1 (int.) & 0.0785 & & - & - \\
\hline S0.6(10-240)T2E & 74.2 & 250 & 750 & 548 & 10 & 240 & 0.57 & 240 & 2 (ext.) & 0.1570 & & - & - \\
\hline S0.6(10-240)T2In & & & & 548 & 10 & 240 & 0.57 & & 2 (int.) & 0.1570 & & - & - \\
\hline SOT3E & & & & - & - & - & - & & 3 (ext.) & 0.2355 & & - & - \\
\hline S1.0(10-140)F1 & & & & 548 & 10 & 140 & 0.97 & & - & - & & 1 & 0.113 \\
\hline S0.6(12-300)F2 & & & & 580 & 12 & 300 & 0.65 & & - & - & 240 & 2 & 0.226 \\
\hline S0F3 & & & & - & - & - & - & & - & - & & 3 & 0.339 \\
\hline
\end{tabular}

\subsection{Material Properties}

\subsubsection{Concrete}

The concrete compressive strength was $f_{c}^{\prime}=74.2 \mathrm{MPa}$. This strength was derived from tests performed on three standard cylinders (150 diameter $\times 300 \mathrm{~mm}$ height) at 28 days after casting. The mixture properties are given in Table 2. All specimens and standard cylinders were casted in a batch plant and kept in a wet curing for seven days and then in an ambient environment until testing. Specimens and standard cylinders had a similar curing procedure.

Table 2. Properties of the concrete mixture.

\begin{tabular}{lc}
\hline Variable & $\mathbf{( k g / \mathbf { m } ^ { \mathbf { 3 } } \mathbf { ) }}$ \\
\hline Cement & 460 \\
Water & 150 \\
Coarse aggregate$-d_{\max }=19$ & 550 \\
Intermediate aggregate- $d_{\max }=9 \mathrm{~mm}$ & 900 \\
Fine aggregate-quartz sand & 220 \\
High-Range Water Reducer & 9 \\
Polypropylene Fibers & 1 \\
Fly Ash & 100 \\
\hline Slump $(\mathrm{mm})$ & 175 \\
Water to cementitious materials $(\mathrm{w} / \mathrm{cm})$ & 0.27 \\
\hline
\end{tabular}

\subsubsection{Textile Fiber-Reinforced Concrete-TRC}

A unidirectional carbon fiber textile mesh (S\&P Armo Mesh L600) was used to produce the textile-reinforced concrete (TRC) confinement. To increase the mesh spacing for a better concrete flow, half of the fiber rovings were cut. Thus, the equivalent thickness was half of that provided by the manufacturer and equaled to $0.157 / 2=0.0785 \mathrm{~mm}$. In order to explore different anchorage systems of the fiber textile mesh, two types of application methods were implemented (before concrete casting): (1) fiber textile mesh wrapped externally around the reinforcement cage (referred to as external TRC_Figures $1 b$ and $2 b$ ), and (2) producing the reinforcement cage with the fiber textile mesh located in the inner perimeter of the cage (referred to as internal TRC-Figure 1c). The anchorage mesh length of the external TRC system was $300 \mathrm{~mm}$ and that of the internal TRC system was $150 \mathrm{~mm}$. The mechanical properties (provided by the manufacturer) of the elastic carbon fiber textile mesh are as follows: modulus of elasticity, $E_{f}=240 \mathrm{GPa}$, ultimate tensile strength, $f_{f u}=4200 \mathrm{MPa}$, and ultimate strain, $\epsilon_{f u}=0.0175$. 


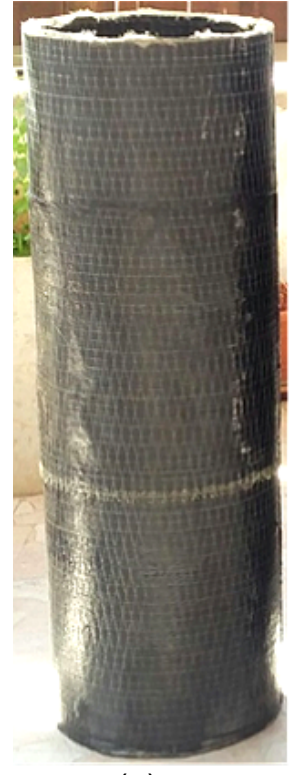

(a)

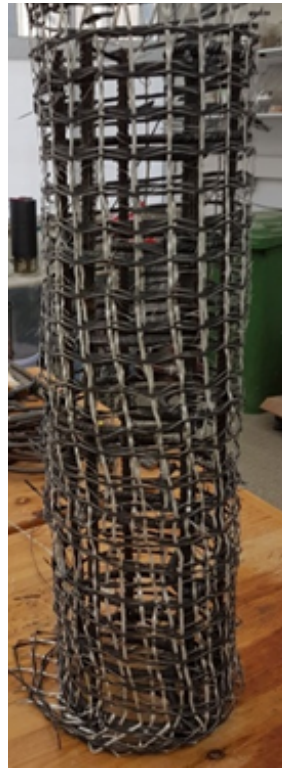

(b)

Figure 2. (a) Stay-in-place FRP tube form; (b) textile fiber wrapped externally around the reinforcement cage.

\subsubsection{Steel Reinforcement}

The specimens with the internal-cage TRC included five deformed bars $12 \mathrm{~mm}$ in diameter and two deformed bars $10 \mathrm{~mm}$ in diameter as longitudinal steel with a reinforcement ratio of $\rho_{s \ell}=1.47 \%$. All other specimens included six longitudinal steel deformed bars $12 \mathrm{~mm}$ in diameter with a reinforcement ratio of $\rho_{s \ell}=1.38 \%$. Steel hoops were used as TSR with deformed bars 10 or $12 \mathrm{~mm}$ in diameter. The spacings of the hoops ranged between $60 \mathrm{~mm}$ [specimen S2.3(10-60)T/F0] and infinity (no TSR - specimens S0T3 and S0F3). Tensile yield strengths of the steel reinforcement bars were derived from three tensile tests of each type (548 and $580 \mathrm{MPa}$ for the 10 and $12 \mathrm{~mm}$ diameter bars, respectively).

\subsubsection{Fiber-Reinforced Polymer-FRP}

Stay-in-place FRP tube forms (Figure 2a) were constructed in a laboratory at the Shamoon College of Engineering (SCE) using carbon fiber sheets (S\&P C-sheet 240, 200 g/ $\mathrm{m}^{2}$ ) with a ply thickness of $0.113 \mathrm{~mm}$. Three tubes were constructed with one, two, and three layers of FRP. The overlap length of the FRP was $150 \mathrm{~mm}$ for all specimens. The linear elastic fiber mechanical properties were provided by the manufacturer: modulus of elasticity $E_{f}=240 \mathrm{GPa}$, ultimate tensile strength, $f_{f u}=4200 \mathrm{MPa}$, and ultimate strain $\epsilon_{f u}=0.0175$.

\subsection{Instrumentation and Test Setup}

All column specimens were tested under compressive loading using a hydraulic press with load-controlled capabilities and a maximum load of $5000 \mathrm{kN}$. The experimental program was performed at the National Building Research Institute laboratory at the Technion - Israel Institute of Technology. The test setup is shown in Figure 3. Around the mid-height of the specimens, strain gauges were installed as follows: two on two longitudinal bars and two hoops, two on the fiber-textile of TRC-TSR specimens (before concreting), and two on the FRP of FRP-TSR specimens. Four linear variable displacement transducers (LVDTs) were used to measure the axial displacement of the specimens during testing - two LVDTs with a gauge length of $575 \mathrm{~mm}$ located on the specimen and two with a gauge length of about $1000 \mathrm{~mm}$ measuring the displacement between the two press loading plates. Steel collars were installed at the two ends of the specimens to prevent local failure and to 
ensure failure at the instrumented zone of the specimens. Sand capping with steel-retaining cups (specially produced for the tests) were used at two ends to ensure uniformity of the loading.

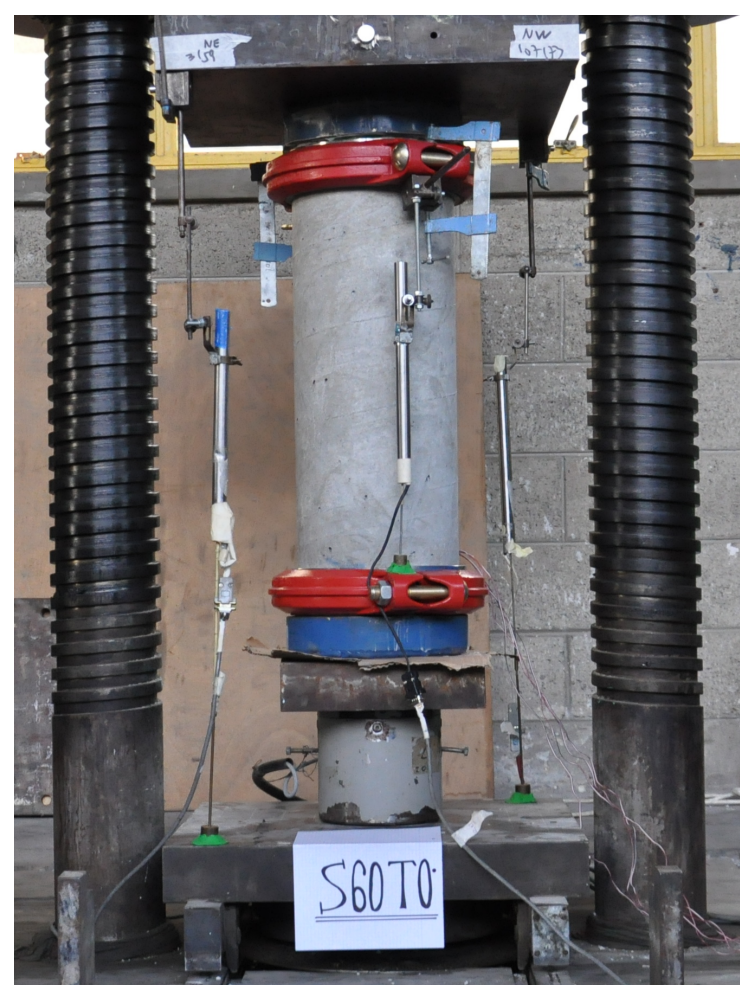

Figure 3. Test setup.

\section{Discussion}

The axial strain versus axial load curves are presented in Figures 4 and 5 and the appearance of all specimens after testing is shown in Figure 6. Table 3 presents measured featured loads and strains of all specimens. The experimental results are discussed in the following sections.

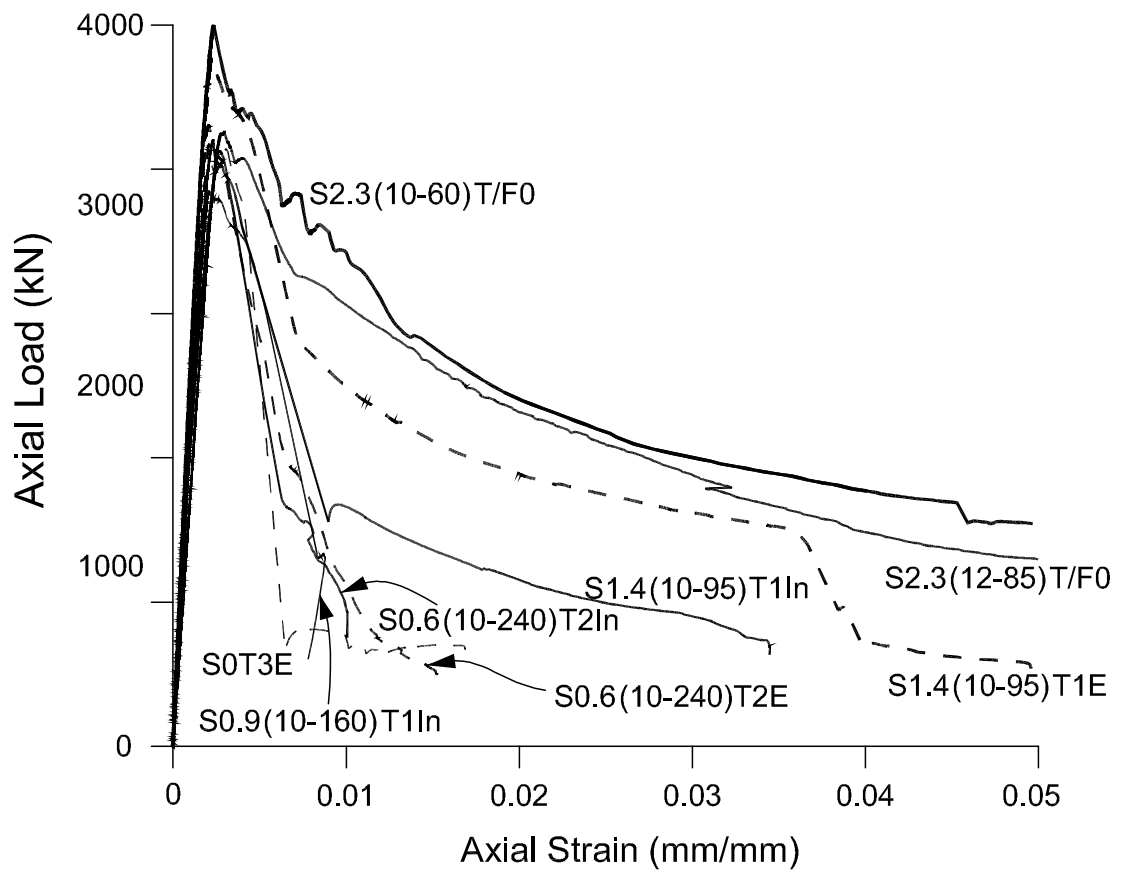

Figure 4. Axial load versus axial strain of TRC-TSR confined specimens. 


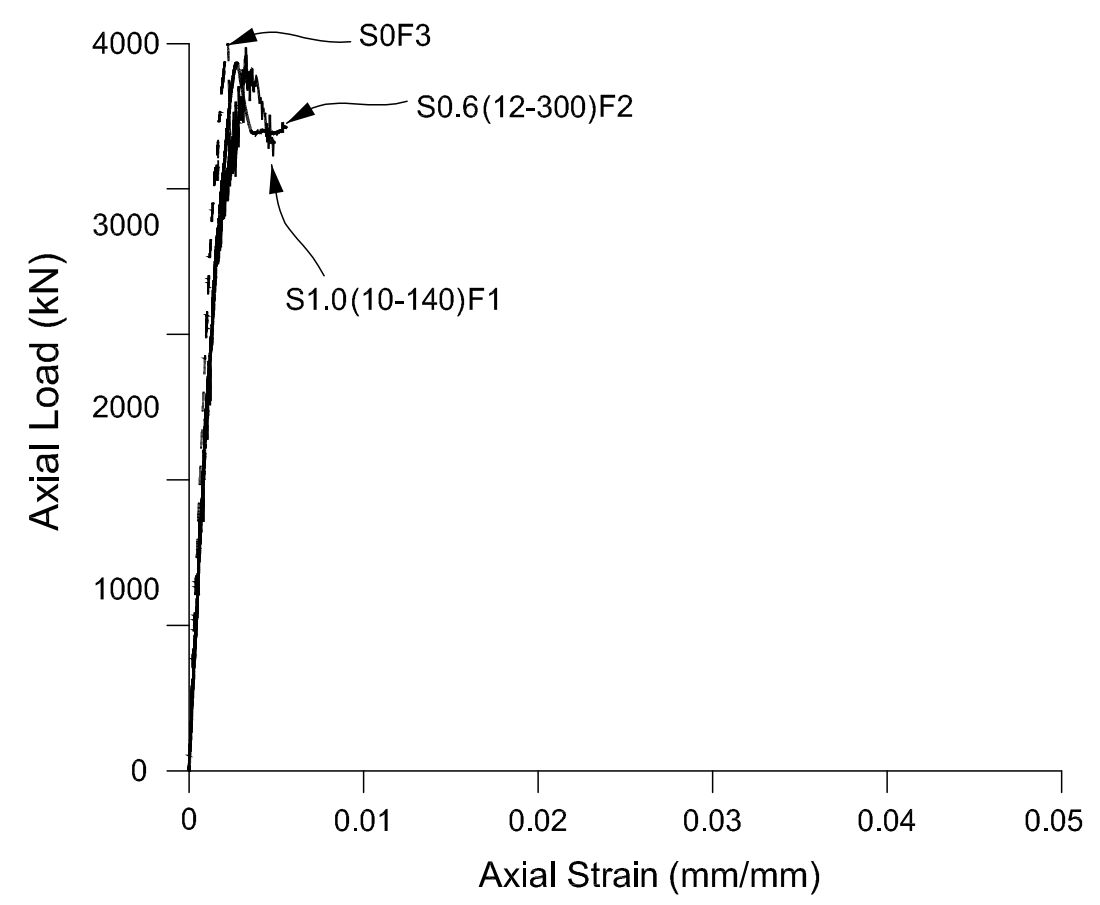

Figure 5. Axial load versus axial strain of FRP-TSR confined specimens.

Table 3. Test results.

\begin{tabular}{|c|c|c|c|c|c|c|c|c|c|c|c|c|}
\hline \multirow[b]{2}{*}{ Specimen } & \multicolumn{6}{|c|}{ Axial Loads } & \multicolumn{6}{|c|}{ Axial Strains } \\
\hline & $\begin{array}{r}P_{\max } \\
(\mathbf{k N})\end{array}$ & $\frac{P_{\max }}{P_{0}}$ & $\begin{array}{c}P_{c 1} \\
(\mathrm{kN})\end{array}$ & $\frac{P_{c 1}}{P_{0 c}}$ & $\begin{array}{l}P_{c 2} \\
(\mathrm{kN})\end{array}$ & $\frac{P_{c 2}}{P_{0 c c}}$ & $\epsilon_{c 1}$ & $\frac{\epsilon_{c 1}}{\epsilon_{c}^{\prime}}$ & $\epsilon_{c 2}$ & $\frac{\epsilon_{c 2}}{\epsilon_{c}^{\prime}}$ & $\epsilon_{c c 50}\left(\epsilon_{c u}\right)^{*}$ & $\frac{\epsilon_{c c 50}}{\epsilon_{c}^{\prime}}\left(\frac{\epsilon_{c u}}{\epsilon_{c}^{\prime}}\right)^{*}$ \\
\hline S2.3(10-60)T/F0 & 3996 & 1.16 & 3677 & 1.20 & 3142 & 1.47 & 0.0024 & 0.87 & 0.0040 & 1.47 & 0.0191 & 7.04 \\
\hline $\mathrm{S} 2.3(12-85) \mathrm{T} / \mathrm{F} 0$ & 3407 & 0.99 & 3023 & 0.99 & 2867 & 1.34 & 0.0030 & 1.09 & 0.0040 & 1.47 & 0.0208 & 7.66 \\
\hline S1.4(10-95)T1E & 3813 & 1.11 & 3515 & 1.15 & 3155 & 1.47 & 0.0022 & 0.81 & 0.0033 & 1.21 & 0.0104 & 3.82 \\
\hline S1.4(10-95)T1In & 3362 & 0.97 & 3029 & 0.99 & 2728 & 1.28 & 0.0023 & 0.85 & 0.0032 & 1.19 & 0.0074 & 2.71 \\
\hline S0.9(10-160)T1In & 3075 & 0.89 & 2778 & 0.91 & 2461 & 1.15 & 0.0021 & 0.76 & 0.0035 & 1.29 & 0.0070 & 2.60 \\
\hline S0.6(10-240)T2E & 3444 & 1.00 & 3167 & 1.04 & 2835 & 1.32 & 0.0020 & 0.75 & 0.0029 & 1.08 & 0.0059 & 2.19 \\
\hline S0.6(10-240)T2In & 3300 & 0.95 & 2925 & 0.96 & 2720 & 1.27 & 0.0026 & 0.96 & 0.0032 & 1.17 & 0.0055 & 2.03 \\
\hline SOT3E & 3338 & 0.97 & 3058 & 1.00 & 2917 & 1.36 & 0.0021 & 0.76 & 0.0030 & 1.11 & 0.0052 & 1.93 \\
\hline S1.0(10-140)F1 & 3979 & 1.15 & 3688 & 1.21 & - & - & 0.0033 & 1.21 & - & - & 0.0049 & 1.82 \\
\hline S0.6(12-300)F2 & 3894 & 1.13 & 3638 & 1.19 & 3129 & 1.49 & 0.0027 & 1.01 & 0.0042 & 1.53 & 0.0056 & 2.06 \\
\hline SOF3 & 3996 & 1.16 & 3713 & 1.22 & 3547 & 1.66 & 0.0022 & 0.82 & 0.0033 & 1.22 & 0.0033 & 1.22 \\
\hline
\end{tabular}

* for specimens $\mathrm{S} 1.0(10-140) \mathrm{F} 1, \mathrm{~S} 0.6(12-300) \mathrm{F} 2$, and $\mathrm{S} 0 \mathrm{~F} 3$, the values refer to $\epsilon_{c u}$ and $\frac{\epsilon_{\mathcal{c} u}}{\epsilon_{c}^{\prime}}$.

\subsection{General}

All specimens behaved similarly at the ascending loading phase. The maximum load, $P_{\max }$, ranged from 3075 to $3996 \mathrm{kN}$. Table 3 shows the ratio of the maximum axial load to the nominal axial load, $P_{\max } / P_{0}$, which ranged from 0.89 to 1.16 , where $P_{0}=0.85 A_{c} f_{c}^{\prime}+A_{s \ell} f_{s \ell}, f_{s \ell}$ is the tensile strength of the longitudinal reinforcement, $A_{c}=A_{g}-A_{s \ell}, A_{g}$, and $A_{s \ell}$ are the cross-sectional area of the concrete, the total section, and the longitudinal bars, respectively. Part of the values of $P_{\max } / P_{0}$ are lower than 1.0. These values are obtained only for the TSR and the TRC-TSR confined specimens. Table 3 also shows $P_{c 1}=$ the maximum load sustained by the concrete, and $P_{c 2}=$ the maximum load sustained by the concrete after the concrete cover spalling off (for TRC-TSR confined specimens) or after the load drop post $P_{\max }$ (for FRP-TSR confined specimens which have no concrete cover spalling off). For all specimens, $P_{c 2}$, was lower than $P_{c 1}$. It should be noted that for one specimen [S1.0(10-140)F1] the applied load decreased after reaching $P_{\max }$ without a change in the slope (thus without having $P_{c 2}$ ) to its failure (due to FRP rupture). The ratios $P_{c 1} / P_{0 c}$ and $P_{c 2} / P_{0 c c}$ range between 0.91 to 1.22 , and 1.15 to 1.66 , respectively, where, $P_{0 c}=0.85 f_{c}^{\prime} A_{c}, P_{0 c c}=0.85 f_{c}^{\prime} A_{c c}$, and $A_{c c}$ is the concrete core cross-sectional area. The TSR-confined specimens reached failure at buckling of longitudinal bars 
and rupture of transverse reinforcement bars. In the TRC-TSR confined specimens, after the first load drop due to spalling off the concrete cover and increasing further the axial strains, the fibers were ruptured resulting in a well-defined second load drop (the higher the TSR amount the smaller the load drop), however, the column continued to sustain smaller loads to the complete failure at buckling of longitudinal bars and rupture of transverse reinforcement bars. It should be noted that the externalas well as the internal-cage TRC-TSR specimens experienced rupture of the fibers. Thus, it can be concluded that the TRC anchorage mechanism of both types is sufficient. In the FRP-TSR confined specimens, after reaching the maximum load, two specimens [S1.0(10-140)F1 and S0.6(12-300)F2] experienced a decrease and one specimen ( $\mathrm{S} 0 \mathrm{~F} 3$ ) experienced a decrease followed by another increase in the load before the failure was defined by the rupture of the FRP. Table 3 also shows the axial strains $\epsilon_{c 1}, \epsilon_{c 2}$, and $\epsilon_{c c 50}$ corresponding to $P_{c 1}, P_{c 2}$, and $50 \%$ of the maximum confined concrete strength, respectively. It is seen from the table that $\epsilon_{c c 50}$ gives a good indication on the ductility of the specimens in compression. The highest $\epsilon_{c c 50}$ values are obtained for the TSR-confined specimens [0.0191 for specimen S2.3(10-60)T/F0 and 0.0205 for specimen S2.3(12-85)T/F0]. The lower the TSR amount, the lower the $\epsilon_{c c 50}$. For the FRP-TSR specimens, Table 3 shows the axial strain at the FRP rupture, $\epsilon_{c u}$. This strain ranged from $\epsilon_{c u}=0.0033$ for the specimen without TSR (S0F3) to 0.0056 for specimen S0.6(12-300)F2.

\subsection{Analysis of Test Results}

Figures 7 and 8 show the normalized stress-strain curves of all specimens. The curves were derived based on a similar technique performed in previous studies $[1,21,22]$. The overall behavior in the figures show that TRC-TSR specimens with the same textile fiber mesh wrapped externally and internally around the reinforcement cage behaved in a similar way. In one case, the external mesh gave a better ductile behavior [compare S1.4(10-95)T1E vs. S1.4(10-95)T1In]. It is shown in Figure 7 that the behavior of specimens S2.3(10-60)T/F0, S2.3(12-85)T/F0, and S1.4(10-95)T1E with $60 \%$ TSR amount and one layer of TRC, is comparable in terms of axial strength and ductility. It should be noted that the amount of TRC was chosen to provide a similar maximum equivalent lateral passive pressure. The effect of TRC on the strength of the specimens is well-observed. For example, compare the confined strength of specimens S0.6(10-240)T2E $\left(P_{c 2} / P_{0 c c}=1.32\right)$ and S2.3(12-85)T/F0 $\left(P_{c 2} / P_{0 c c}=1.34\right)$. However, in terms of ductility, the behavior of the latter specimens are not similar. Thus, the effect of the TRC confinement on the ductility enhancement is not as effective as the TSR confinement. This is a result of the low actual maximum tensile strain reached by the TRC (linear-elastic material) in all TRC-TSR confined specimens, $\epsilon_{f u, a}\left[\epsilon_{f u, a} \approx(0.3-0.6) \epsilon_{f u} \approx 0.005-0.01\right]$, compared to the high strains that can be reached by the TSR (elastic-perfectly plastic material). Thus, it is recommended to further examine higher amounts of TRC combined with TSR in order to reach a similar ductile behavior as the TSR's only confined specimens.

Figure 8 shows that in terms of axial strength, the FRP-TSR specimens obtained the highest maximum loads. This is attributed to the prevention of the cover spalling off by the FRP action. However, in terms of ductility, the FRP-TSR specimens were unable to sustain loads after the rupture of the FRP (at $\epsilon_{f u, a} / \epsilon_{f u} \approx 0.3-0.46$ ). 


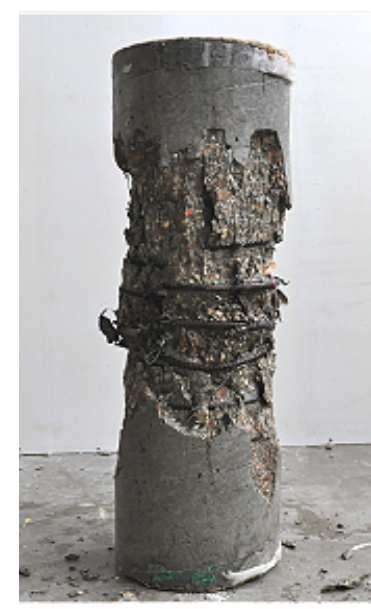

S2.3(10-60)T/F0

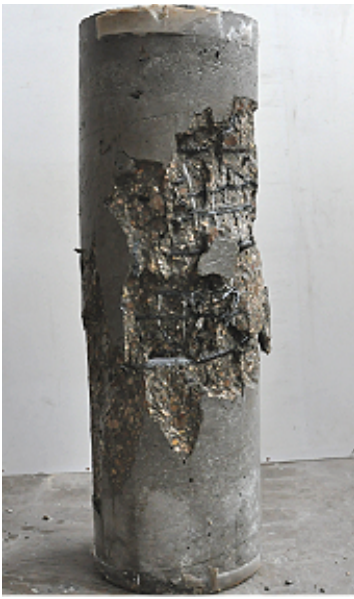

S0.9(10-160)T1In

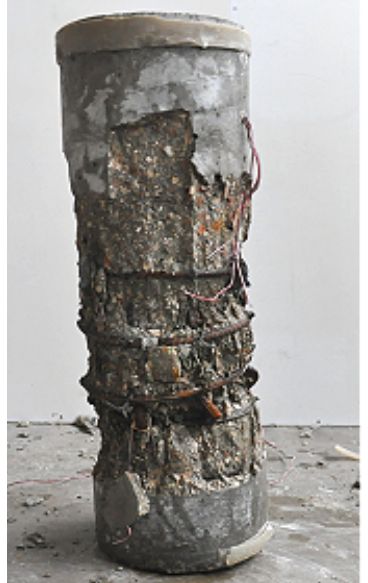

S2.3(12-85)T/F0

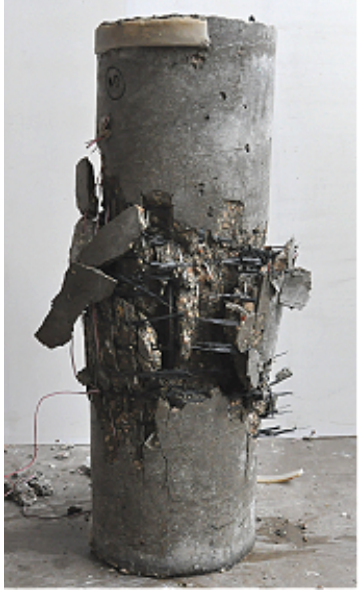

S0.6(10-240)T2E

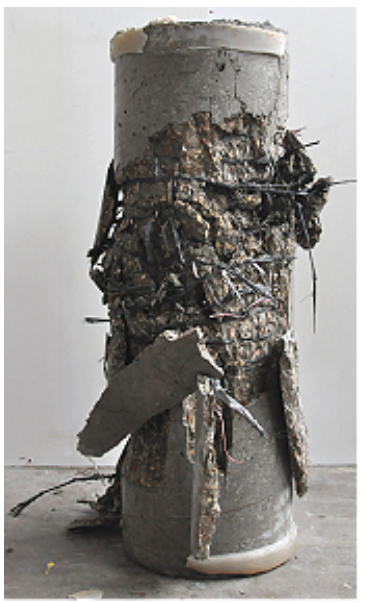

S1.4(10-95)T1E

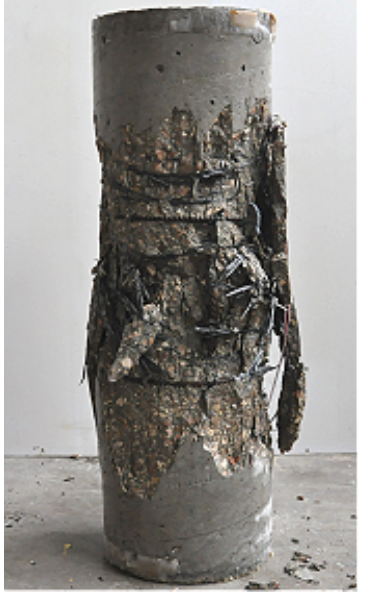

S0.6(10-240)T2In

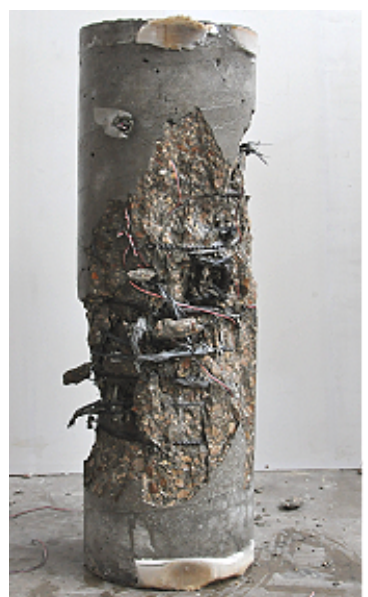

S1.4(10-95)T1In

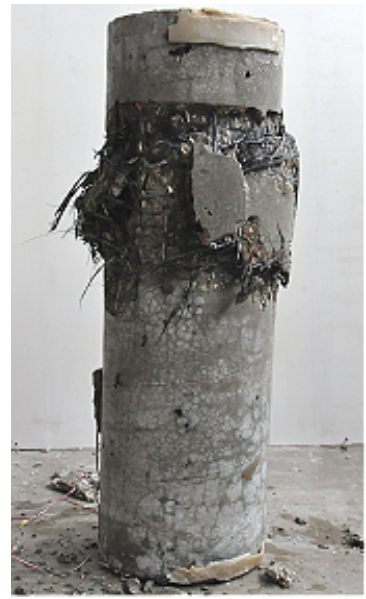

SOT3E

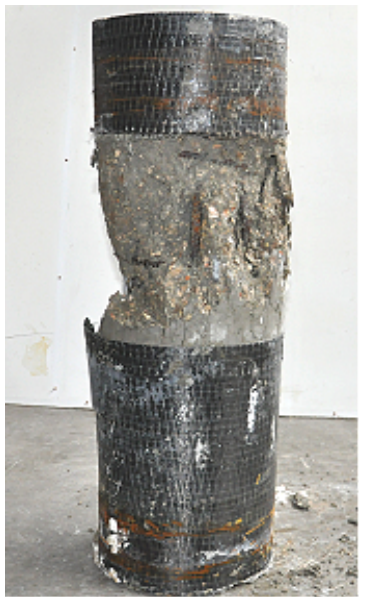

S1.0(10-140)F1

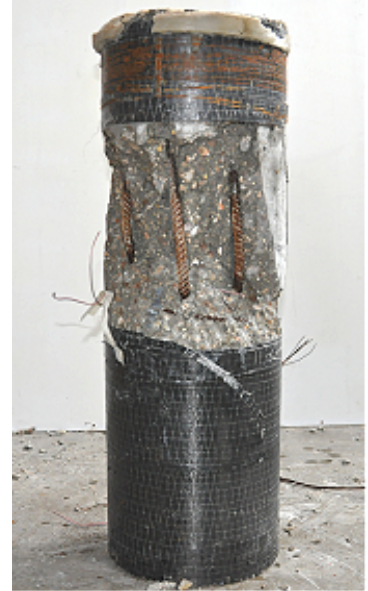

S0.6(12-300)F2

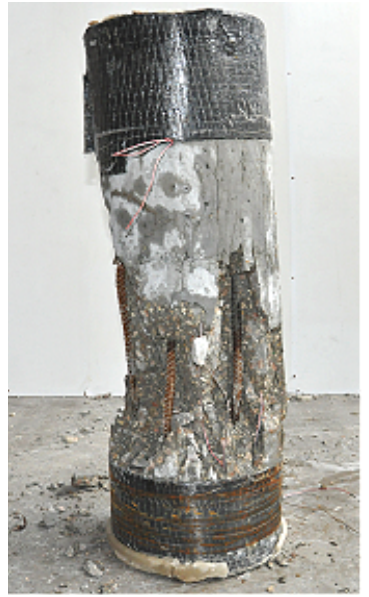

S0F3

Figure 6. Specimens after testing. 


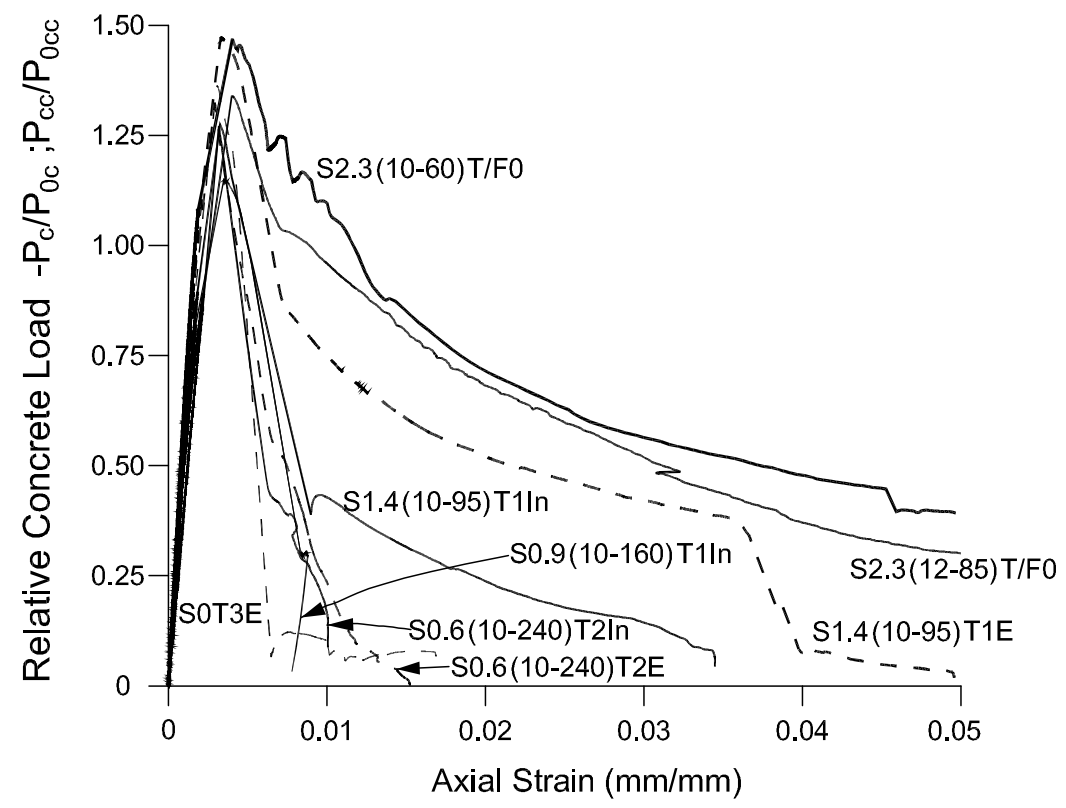

Figure 7. Normalized stress-strain curves of TRC-TSR confined specimens.

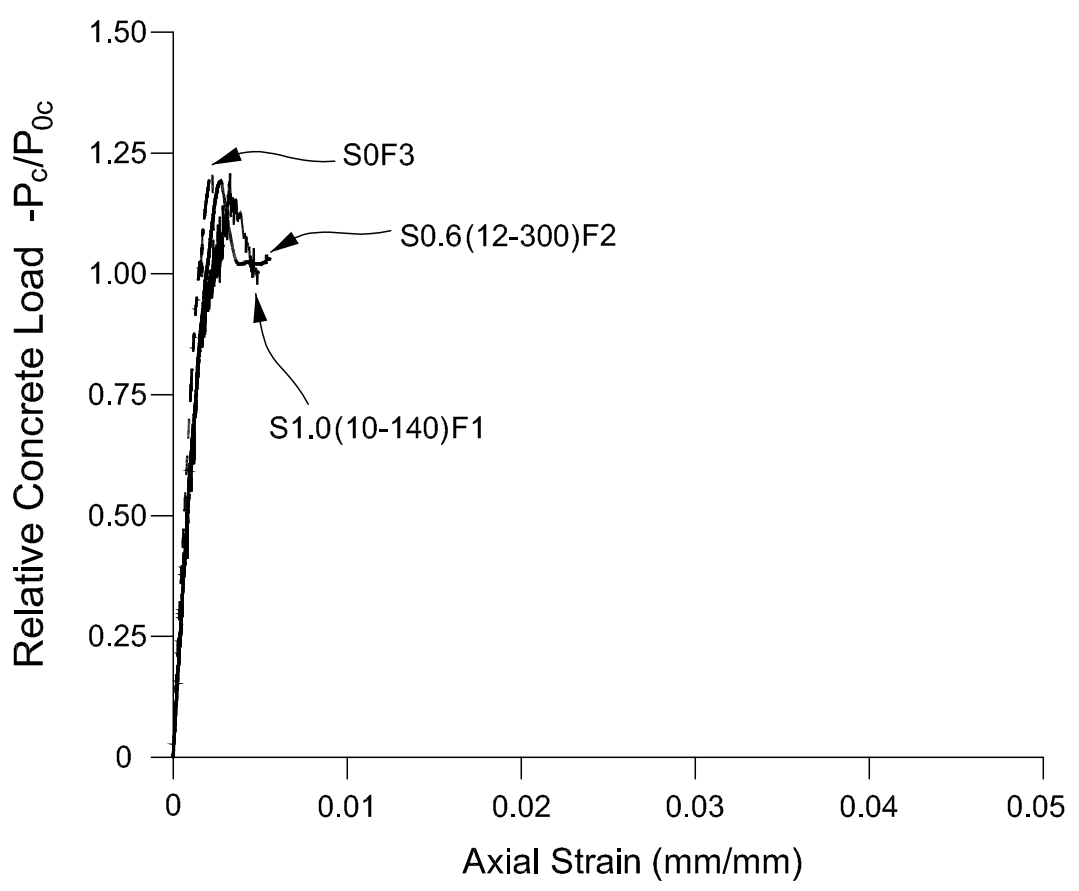

Figure 8. Normalized stress-strain curves of FRP-TSR confined specimens.

\section{Conclusions}

Studies have shown that the amount of transverse steel reinforcement (TSR) in HSC columns are, in some cases, impractical with regard to construction aspects. This paper proposed a new confinement configuration of fiber textile reinforced concrete (TRC) with conventional TSR, both as internal reinforcement. An experimental research study was performed on eleven large-scale HSC circular column specimens subjected to axial compression loading. The specimens include three different confinement configurations: conventional TSR, stay-in-place FRP-TSR, and TRC-TSR with similar confinement levels. It has been shown that in terms of strength, the efficiency of the dual confinement system, TRC-TSR, was well-observed. Nonetheless, in terms of strength, the FRP-TSR system was more efficient than the conventional TSR or the TRC-TSR system. This is attributed to the fact that the FRP tube prevents premature spalling off the concrete cover, which is a well-known 
phenomena in HSC columns. However, in terms of ductility, it is shown that the combination of TRC-TSR confinement (with a moderate amount of TSR) can provide comparable behavior to that of conventional TSR-confined specimens. Nonetheless, it should be noted that the ductility behavior was low for TRC-confined columns with low amounts of TSR. Therefore, the effect of the TRC confinement on the ductility enhancement was not as effective as the TSR confinement. This is a result of the low actual maximum tensile strain reached by the TRC in all TRC-TSR confined specimens compared to the high strains that can be reached by the TSR. It is recommended to further examine higher amounts of TRC combined with TSR in order to reach a similar ductile behavior as the TSR only confined specimens.

Author Contributions: Conceptualization, R.E., E.I., N.L. and A.Z.; methodology, R.E.; validation, R.E., A.C., R.G., E.I., N.L. and A.Z.; formal analysis, R.E., A.C., R.G., E.I., N.L. and A.Z.; investigation, R.E., A.C., R.G., E.I., N.L. and A.Z.; resources, R.E., A.C., R.G., E.I., N.L. and A.Z.; data curation, R.E., A.C., R.G., E.I., N.L. and A.Z.; writing-original draft preparation, R.E.; writing—review and editing, R.E.; visualization, R.E., N.L., and A.Z.; supervision, R.E.; project administration, R.E.; funding acquisition, R.E.

Funding: This research was funded by SCE—Shamoon College of Engineering Excellent Research grant number 10/Y16/T2/D1/Yr2.

Acknowledgments: The authors would like to thank Ami Dahan from Israbeton Concrete-part of Ashtrom Industries, for his collaboration and important role in this research study. Moreover, the technical assistance of Haim Dahan from the Civil Engineering Department at SCE_-Shamoon College of Engineering, and Yakov Vitman, Elhanan Izhak, and Eddi Gershengoren from the National Building Research Institute at the Technion-Israel Institute of Technology, is gratefully acknowledged.

Conflicts of Interest: The authors declare no conflict of interest.

\section{Abbreviations}

The following abbreviations are used in this manuscript:

TRC Textile reinforced concrete

TSR Transverse steel reinforcement

FRP Fiber-reinforced polymer

NSC Normal-strength concrete

HSC High-strength concrete

RC Reinforced-concrete

SFRS Seismic-force-resisting system

\section{References}

1. Eid, R.; Kovler, K.; David, I.; Khoury, W.; Miller, S. Behavior and design of high-strength circular reinforced concrete columns subjected to axial compression. Eng. Struct. 2018, 173, 472-480. [CrossRef]

2. Légeron, F.; Paultre, P. Behavior of High-Strength Concrete Columns under Cyclic Flexure and Constant Axial Load. ACI Struct. J. 2000, 97, 591-601.

3. Paultre, P.; Eid, R.; Robles, H.I.; Bouaanani, N. Seismic Performance of Circular High-Strength Concrete Columns. ACI Struct. J. 2009, 106, 395-404.

4. Aslani, F.; Nejadi, S. Cyclic Constitutive Model for High-Strength Concrete Confined by Ultra-High-Strength and Normal-Strength Transverse Reinforcements. Aust. J. Struct. Eng. 2012, 12, 159-172.

5. American Concrete Institute ACI 318. Building Code Requirements for Structural Concrete; ACI: Farmington Hills, MI, USA, 2014.

6. New Zealand Standard 3101. Concrete Structures Standard, Part 1-The Design of Concrete Structures; Standards New Zealand: Wellington, New Zealand, 2006.

7. Canadian Standard Association (CSA) A23.3. Design of Concrete Structures; CSA: Mississauga, ON, Canada, 2014.

8. $\quad$ European Standard EN 1998-1. Eurocode 8: Design of Structures for Earthquake Resistance. Part 1: General Rules, Seismic Actions and Rules for Buildings; European Committee For Standardization: Brussels, Belgium, 2004. 
9. Ozbakkaloglu, T.; Oehlers, D.J. Concrete-Filled Square and Rectangular FRP Tubes under Axial Compression. ASCE J. Compos. Constr. 2008, 12, 469-477. [CrossRef]

10. Ozbakkaloglu, T. Axial Compressive Behavior of Square and Rectangular High-Strength Concrete-Filled FRP Tubes. ASCE J. Compos. Constr. 2013, 17, 151-161. [CrossRef]

11. Han, L.H.; Zheng, Y.Q.; Teng, J.G. Fire resistance of RC and FRP-confined RC columns. Mag. Concr. Res. 2006, 58, 533-546. [CrossRef]

12. Echevarria, A.; Zaghi, A.E.; Christenson, R.; Plank, R. Residual Axial Capacity Comparison of CFFT and RC Bridge Columns after Fire. Polymers 2015, 7, 876-895. [CrossRef]

13. Firmo, J.P.; Correia, J.R.; Bisby, L.A. Fire behaviour of FRP-strengthened reinforced concrete structural elements: A state-of-the-art review. Compos. Part 2015, 80, 198-216. [CrossRef]

14. Triantafillou, T.C.; Papanicolaou, C.G.; Zissimopoulos, P.; Laourdekis, T. Concrete confinement with textile-reinforced mortar jackets. ACI Struct. J. 2006, 103, 28-37.

15. Bournas, D.A.; Lontou, P.V.; Papanicolaou, C.G.; Triantafillou, T.C. Textile-reinforced mortar versus fiber-reinforced polymer confinement in reinforced concrete columns. ACI Struct. J. 2007, 104, 740-748.

16. Ortlepp, R.; Ortlepp, S. Textile reinforced concrete for strengthening of RC columns: A contribution to resource conservation through the preservation of structures. Constr. Build. Mater. 2017, 132, 150-160. [CrossRef]

17. Liu, M.; Yin, S.-P.; Cong, X. Seismic behavior of textile-reinforced concrete-strengthened RC columns under different axial compression ratios. J. Eng. Fibers Fabr. 2019, 14, 1-11.

18. Al-Gemeel, A.N.; Zhugea, Y. Using textile reinforced engineered cementitious composite for concrete columns confinement. Compos. Struct. 2019, 210, 695-706. [CrossRef]

19. Cerniauskas, G.; Tetta, Z.; Bournas, D.; Bisby, L.A. Textile reinforced mortar versus FRP for confined concrete: Behaviour at elevated temperatures. In Proceedings of the 8th International Conference on Fibre-Reinforced Polymer (FRP) Composites in Civil Engineering (CICE 2016), Hong Kong, China, 14-16 December 2016.

20. Eid, R.; Cohen, A.; Guma, R.; Ifrach, E.; Levi, N.; Zvi, A. Multi-layer TRC-TSR internal confinement for high-strength circular reinforced-concrete columns. In Proceedings of the 9th International Conference on Fibre-Reinforced Polymer (FRP) Composites in Civil Engineering (CICE 2018), Paris, France, 17-19 July 2018.

21. Eid, R.; Roy, N.; Paultre, P. Normal- and high-strength concrete circular elements wrapped with FRP composites. ASCE J. Compos. Constr. 2009, 13, 113-124. [CrossRef]

22. Cusson, D.; Paultre, P. High-Strength Concrete Columns Confined by Rectangular Ties. ASCE J. Struct. Eng. 1994, 120, 783-804. [CrossRef]

(C) 2019 by the authors. Licensee MDPI, Basel, Switzerland. This article is an open access article distributed under the terms and conditions of the Creative Commons Attribution (CC BY) license (http://creativecommons.org/licenses/by/4.0/). 